\title{
The fortifications of Sydney, Australia: adaptive re-use and issues around public access
}

\author{
P. R. Davies \\ Paul Davies Pty Ltd. Architects Heritage Consultants, Balmain, Australia
}

\begin{abstract}
This paper examines the fortifications around Sydney Harbour and Botany Bay in Sydney, Australia, particularly in regard to how they are to be managed into the future with the cessation of military use and their incorporation into Sydney Harbour National Park. The paper looks at use, conservation, maintenance, occupational health and safety, public access and risk management and strategic approaches to management and adaptive re-use.

Keywords: conservation, adaptive re-use, occupational health and safety, strategic planning, significance, interpretation, maintenance.
\end{abstract}

\section{Overview of history of Sydney fortifications}

Settled in 1788 by the British with minimal supplies and personnel, Sydney commenced protecting itself quickly with the first fortifications built overlooking Sydney Cove using guns from the supply ships. The batteries were earth formed and quite fragile and were located close to and around the settlement site. Protection was sought against the French (Napoleonic Wars) from Irish convicts transported after the 1798 rebellion, Spanish ships in the east, the American colonies and later fear of Russian invasion followed by Italian, German and Japanese invasions.

1800 saw the first more remote battery at Georges Head, cut out of the rock escarpment. This was the first permanent construction. Some further construction took place up to 1850 with more substantial structures replacing earlier batteries but despite much discussion and argument, the protection of Sydney did not greatly progress as the British Government, pre-occupied with wars and internal issues, lost interest in funding the protection of such a remote settlement. 
The first major construction of a co-ordinated set of fortifications took place in the 1870s. With the complex geography of the harbour, outer and inner defences were established on the major and minor headlands of the harbour north, south and middle heads for outer defences and the smaller promontories and islands for inner defences. To the south of Sydney, Botany Bay also attracted major fortifications, with an island and other defensive positions near the entrance to the bay being developed, to protect Sydney from overland attack from boats avoiding Sydney Harbour and landing in Botany Bay.

Further fortifications were added to most of the earlier sites in the 1880's, the 1890 's and leading up to WWI. With the threat of Japanese invasion a major new layer of fortifications was added prior to and during WWII including submarine nets and radar installations. The only significant attack on Sydney in its history was by miniature Japanese submarines during WWII.

Often earlier fortifications were adapted or built upon for new installations, sometimes earlier sites were abandoned with new sites adjacent and some sites were demolished or infilled as part of upgrade work. Largely abandoned after the second world war, but remaining on defence owned land, the fortification sites gradually deteriorated, had their ordinance and infrastructure removed, became overgrown and were not accessed or used. An exception was the use of some of the underground tunnels and structures to train troops for guerrilla warfare during the Vietnam War and the ongoing use of buildings suitable for staff accommodation.

The extensive land holdings that accompanied the fortifications however, continued in use for military purposes until the 1970s when most, but not all, of the defence lands were transferred from the Australian Federal Government (responsible for defence) to the NSW State Government to create (in part) the Sydney Harbour National Park. Since that time further assets have been transferred with now only relatively small military holdings remaining. All of the historic fortification sites are now removed from defence use and ownership.

The large holdings were, for the most part, in poor condition and there was little funding allocated to undertake works on most sites. Features that did attract works and funding have been the buildings, particularly residential buildings that have accommodated staff and office functions (mostly timber framed and clad), defensive features with easy public access at major lookout locations, several of the large installations that have been recognised as rare and which required urgent works to prevent their loss.

\section{What remains}

There are 13 separate sites within the management of the NPWS and several other sites managed by other agencies. Management and use issues are similar across all sites.

The sites are:

$\begin{array}{ll}\text { BARE ISLAND } & - \text { access bridge } \\ \text { (Botany Bay) } & -1877-1886 \text { and later as a whole island } \\ & -1889 \text { barracks building }\end{array}$




$\begin{array}{ll}\text { BRADLEY'S HEAD } & -1839 \text { harbour front fortifications } \\ & -1870 \text { s fortifications including rifle post wall } \\ & - \text { WWII lookout and anti-aircraft gun emplacement } \\ \text { CAPE BANKS } & - \text { c1940 above ground remains }-2 \text { g. } \\ & \text { emplacements } \\ \text { (Botany Bay) } & - \text { c1940 below ground remains } \\ \text { FORT DENISON } & -1790 \text { 0nwards } \\ \text { GREEN POINT } & -1871 \text {-1885 battery } \\ & - \text { post } 1892 \text { battery } \\ & - \text { WWII anti-submarine features } \\ \text { GAP BLUFF } & - \text { c1912 gunnery training wall } \\ \text { GEORGES HEAD } & -1879 \text { casemate } \\ & -1886 \text { armoured casemate group } \\ & -1942 \text { WWII searchlight, lookout posts and guns } \\ \text { HENRY HEAD } & -1877 \text { Henry Head Fort } \\ \text { (Botany Bay) } & - \text { WWII Searchlights and lookout posts }\end{array}$

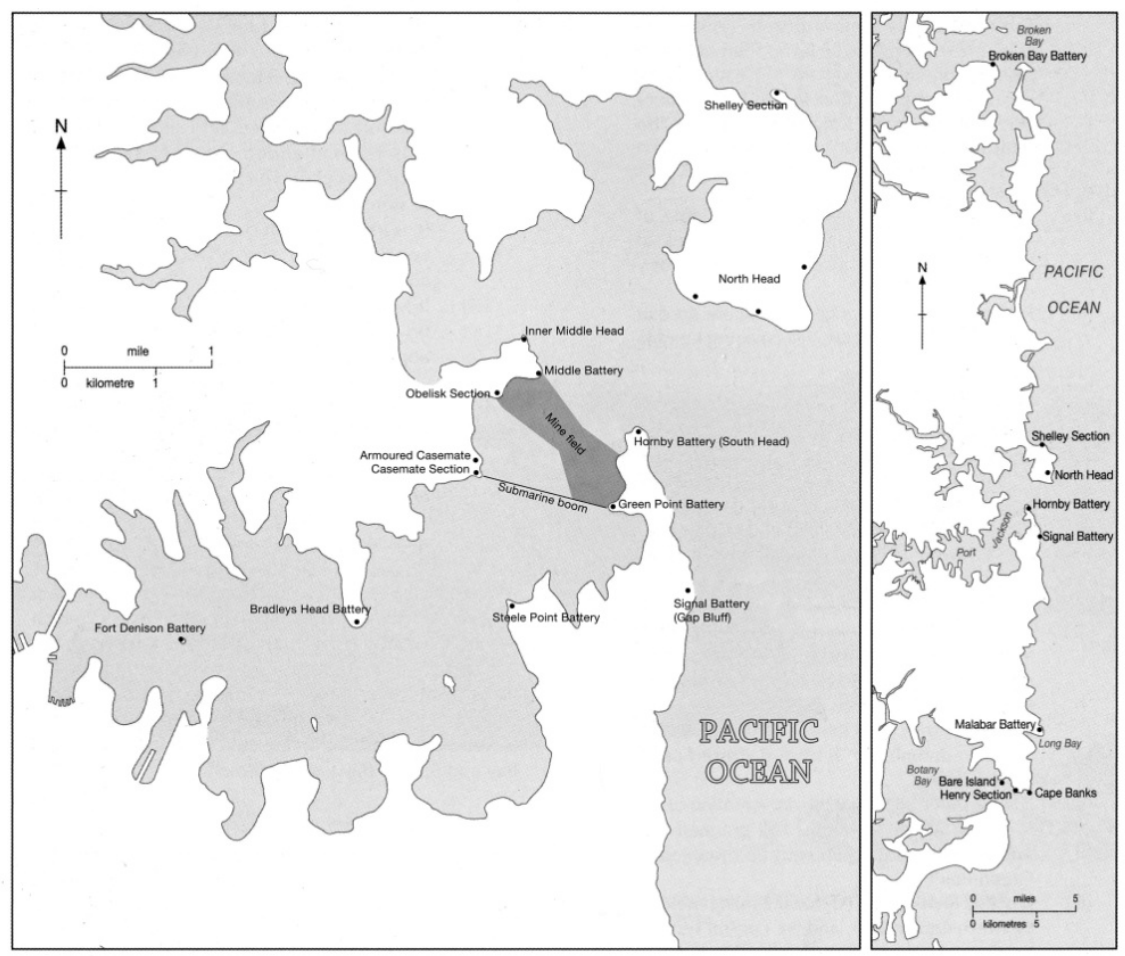

Figure 1: Map showing the major fortifications around Sydney managed by NPWS. 


$\begin{array}{ll}\text { MIDDLE HEAD } & -1871 \text { onwards (inc WWI, WWII) inner forts } \\ \text { NORTH HEAD } & -1853 \text { onwards (inc WWI, WWII) outer forts } \\ & -1941 \text { Blue Fish radar station } \\ \text { OBELISK POINT } & - \text { WWII Headland lookouts and searchlights } \\ & -1801 \text { battery } \\ & -1889 \text { submarine miners observation post } \\ & - \text { WWII case battery features } \\ \text { SOUTH HEAD } & -1871 \text { battery and engine house } \\ & - \text { WWI AND WWII cliff edge structures } \\ \text { STEELE POINT } & - \text { sandstone drainage moat and rifle post wall } \\ & -1871 \text { and later fortifications. }\end{array}$

\section{Assessment of significance}

All decisions about the management and future of places of heritage significance must be made within the framework of understanding their significance. It is therefore necessary to set out what that significance is using the criteria of the heritage legislation under which they are listed and protected. A summary statement of significance for the whole collection of defence sites in Sydney is:

The fortifications of Sydney Harbour and Botany Bay are of exceptional significance for their collective ability to demonstrate all aspects of the fortifying of first the remote colonial settlement of Sydney and later the port and main defence of the State and Commonwealth based in Sydney Harbour.

The elements range in age from 1801 to the Vietnam War and exhibit complete and intact installations from each phase of the development of fortifications as well as extensive layering of sites over each other as the need for defences changed. Although most of the ordnance has now been removed from sites they retain the ability to graphically present how Sydney was fortified and provide opportunities for interpretation of the development and defence of Sydney from 1800 to the present day.

The fortifications collectively demonstrate the political climate of each major stage of works as the relationship between the colony and Great Britain was defined and New South Wales and later Australia increasingly became independent of British support following the withdrawal of Imperial troops and the need for the colonies to provide their own defences. The various developments also demonstrate the ineptitude of much of the British advice that was given with nearly all of the Victorian fortifications redundant by the time they were constructed. While the early structures are impressive in their scale and engineering they were largely ineffective as defences. In contrast the later twentieth century installations, while not being required to engage in active defence, were more suitable and pragmatic as responses to potential threats.

The early fortifications, in particular, also provide important insights into the perceived vulnerability of the early colony where threats were seen from Napoleon, Russia, the Americas and the French. While none of these eventuated, largely due to the distance of New South Wales from any potential enemy, it is unlikely that the fortifications would have provided effective protection if there had been an attack.

The fortifications, particularly as a group, provide the largest collection of fortifications in Australia and are nearly all related visually and functionally occupying the key headlands in the Harbour and Botany Bay. Their inter-relationship, which was 
functionally required to provide protection to the Harbour, has the potential to be interpreted.

Each site within the group provides important historical technical information about design, construction and operation of the fortifications and each site has archaeological potential with many features infilled and new features being uncovered over time.

The development of fortifications in Sydney is associated with many prominent people over a long period of time. Key political and military figures were associated with the developments along with military advisers and designers such as Scratchley and Jervois from England and important local designers such as Barnet.

All of the sites fall within the Sydney Harbour National Park and have important natural values in addition to their cultural heritage values. They are all sites of outstanding scenic beauty and interest, most are prominent lookouts that provide panoramic views to the Harbour, a number of sites are within established parks with high levels of visitation.

\section{Issues affecting defence sites}

Over the 30 years that the fortification sites have been part of the Sydney National Park, considerable work has been undertaken to study the sites, determine what is there, assess their heritage significance and, in specific cases, undertake conservation and repair and maintenance works to ensure the longterm retention of those elements. However, much of the work has been random in that a few buildings, features and sites have received extensive study and conservation work while others have received none. Priority has been given to the most important and rare sites and those with highest tourist potential, but even those sites continue to have ongoing maintenance and conservation issues with almost no use or clear proposals for future use. The key issues that confront the managers of these sites are:

- the extensive collection of sites that are not geographically connected

- varying management regimes for differing sites

- other priorities than built heritage as part of a National Park system

- limited budgets across the sites and no budget on some sites

- a large range of conservation and maintenance issues, many individual sites requiring detailed specific solutions to issues

- a high level of deterioration of some site types, particularly those using steel or steel reinforcing that is now reaching a critical stage in that structures are dangerous and at risk of collapse.

- most structures are not capable of adaptive re-use and have no potential for income production to assist in their conservation and maintenance.

\section{Strategic approach}

Several years ago I prepared a strategic approach for NPWS to manage these sites. The recommendations in that report provide an approach to managing a redundant, remote, dangerous and at risk collection of very significant places. 


\subsection{Strategies and recommendations}

The strategies proposed, with a rating of priority were:

\section{Strategic direction - HIGH PRIORITY}

1 Recognise that the sites comprising the fortifications of Sydney that are managed by NPWS are of exceptional heritage value to Sydney, NSW and Australia and that they should be managed to achieve their potential as part of the unique setting of the Harbour and Botany Bay.

2 Recognise that the number of sites, the extent of the features within each site and their high conservation and management needs will limit the amount of work that can be undertaken and agree on the following priorities across all sites:

3 Secure all sites to the levels required to prevent unsafe access.

4 Remove unacceptable $\mathrm{OH}+\mathrm{S}$ risks as identified in this report and through more detailed later assessments.

5 Undertake urgent stabilisation works (or undertake partial removal of elements) where there are risks of collapse or failure.

6 Establish site monitoring and reporting to all sites.

7 Implement a maintenance plan for each site.

8 Focus major conservation works, upgrade, interpretation programs, marketing and funding applications at Bare Island and Middle/ Georges Head sites in the immediate to medium term future. Only develop further programs when these sites are operational and being successfully managed.

\section{Key sites approach - HIGH PRIORITY}

1 At Bare Island investigate potential commercial activity to support and assist the site (that is consistent with the plan of management). Re-establish tours at times to be determined based on need and time of year. Investigate valueadding tours with activities such as diving on the island, potentially staying on the island, night tours, etc. as part of a longer-term strategy. Develop the site as a core fortification site within the Sydney area.

2 At Middle/Georges Head develop a linked, self guided tour and managed guided tours that extend from the NPWS offices at Middle Head to the inner fortifications including the below ground areas, the outer fortifications, the defensive ditch, the 1801 fort, past the Obelisk Point WWII features, through the casemates possibly terminating at the Chowder Bay site (not NPWS ownership). Connect sites with a new walkway/track (using existing routes where possible) that provides safe and managed access to sites selected for access. Provide interpretation en route. Link the tour to natural values, tourism etc.

3 Develop a marketing strategy for the sites, for public access and for tourism to raise visitation numbers and to provide support facilities and activities.

4 Programs should focus on providing enhanced public access, safety, interpretation linked to initial conservation works where required.

5 Focus on providing organised tours that take advantage of the fortifications and the spectacular locations to promote NPWS values both built and natural. 
6 Provide well designed and presented written material at these two sites with clear identification of sites, access routes, history, resources available to allow for self-guided tours as well as organised tours.

\section{Management, reports and planning - HIGH PRIORITY}

1 Consolidate and index all reports and written work related to the fortification sites.

2 Prepare a review of written material at each site (this has been undertaken at one site) to allow comparison of work already undertaken prior to undertaking further reports and studies. This will also allow varying recommendations to be assessed.

3 Update the NPWS Heritage register for all of the fortification sites. Provide clear site and feature identification and mapping.

4 Establish a conservation works program across all sites. Identify common issues, look for economies of scale in addressing specific and detailed problems. Stage the works based on priorities but also strategic policies. Initially address urgent stabilisation and make-safe works to all sites.

5 Establish an annual maintenance program across all sites.

6 Establish a monitoring program and annual reporting system across all sites.

7 Undertake specific staff training for staff involved in managing fortification sites.

8 Provide higher levels of security to 'at-risk' sites as a matter of urgency.

9 Approaches to $\mathrm{OH}+\mathrm{S}$ issues and risk management need to be clearly articulated to achieve a consistent approach across the sites and to ensure that NPWS has clearly set out the basis of risk management for the fortifications which are sites that have potentially high visitation and which are in often difficult locations.

10 Appoint a staff member to have responsibility for the overall oversight of the fortifications, reports and works so that all the sites are considered as a group.

11 Establish a common approach to the assessment of significance across all sites.

\section{Management, reports and planning - MEDIUM PRIORITY}

12 Establish a central repository for reports with copies in relevant local offices.

13 Undertake a review of all plans and reports more than three years old, commencing with older plans and documents to assess their appropriateness for current use. Establish a review program for documents that require updating.

14 Commission a thematic history, with a view to publication, covering the whole of the defence setting of Sydney.

15 Consolidate data sheets for each element of each site on a common database with updated information. Use this as the basis for future works and monitoring.

16 Consolidate all known heritage listings and citations related to the sites.

17 Extract detailed advice and recommendations on conservation and maintenance from reports and studies, review and consolidate into the database of property files. 
18 Establish a template for future plans and upgrades to ensure consistency of approach and information provided.

\section{Finance - HIGH PRIORITY}

1 Establish budgets to undertake the above programs.

2 Develop an overall package of works, access and interpretation and seek special funding to undertake works of national significance at the two key sites.

3 Develop a strategic approach to government to seek major works funding for key sites linked to other government strategies for tourism, etc.

4 Identify works that can be undertaken without significant additional funding, in particular maintenance, security and monitoring and commence immediately.

Arising from this were site specific approaches that varied from detailed conservation and interpretation/use proposals to demolition, partial demolition and infilling of dangerous sites. Many of the strategies may seem obvious, but my experience is that complex government organisations, that are subject to political and internal change on a regular basis, find it difficult to develop longterm strategic approaches as budgets are usually annual, limiting planning to the immediate, and agencies tend to be re-active rather than pro-active.

\subsection{Maintenance}

A key aim was to develop simple techniques to allow any staff member, skilled or unskilled in conservation, to manage the sites with some success. To achieve this, pro-formas were developed for each site with weekly, monthly and annual check-lists on maintenance and safety issues so that if only that list of works were achieved the place would be at least secure and safe. These were separate from the strategy report so that field staff could take them to site and use them without having to read the whole strategy.

Each major feature of each site was also considered for conservation and maintenance actions with a high, medium and low priority set out. An example is Henry Head, a remote (that is not near other development nor in an area that is regularly managed or monitored) and unmanaged collection of elements. While the elements are excellent examples of their type, there are other better sets of infrastructure in locations with high potential visitation and with easy public access. The strategy there is to minimally manage, make safe, let WWII elements continue to deteriorate and slowly remove them as they fail and focus on other higher significance sites.

A second and contrasting site is Middle Head, possibly the most important and complex of the defence sites in NSW. The strategy for this site is for it to be the focus of a major funding in the future to provide high levels of public access, interpretation, safety and ancillary uses. This links to its spectacular setting with views over Sydney and the harbour that attracts more visitors to the location than the fortifications. The strategy for the outer fortifications is: 
Table 1: $\quad$ Outer middle head maintenance priorities.

\begin{tabular}{|c|c|}
\hline Description and Existing Condition & Recommendations/Priority \\
\hline \multicolumn{2}{|l|}{ OUTER MIDDLE HEAD } \\
\hline $\begin{array}{l}\text { Outer Middle Head is the most complex site } \\
\text { examined with its high level of visitation, layers of } \\
\text { development and range of facilities. There are many } \\
\text { conservation needs across this site covering most } \\
\text { areas and materials. The key matter is to prepare a } \\
\text { staged conservation works program to ascertain } \\
\text { need, priority and costing. This needs to be balanced } \\
\text { with the ruined character of the site that will over } \\
\text { time see some elements deteriorate. }\end{array}$ & $\begin{array}{l}1 \text { Prepare a staged conservation } \\
\text { works program to ascertain need, } \\
\text { priority and costing. } \\
\text { HIGH }\end{array}$ \\
\hline $\begin{array}{l}\text { - } 1871-1882 \text { battery remains } \\
\text { - } 1882-1892 \text { modifications } \\
\text { - } 1892-1911 \text { emplacements } \\
\text { - } 1912-1945 \text { battery } \\
\text { - Post } 1945 \text { elements } \\
\end{array}$ & \\
\hline $\begin{array}{l}\text { This report addresses key areas only in terms of } \\
\text { conservation work and does not attempt to separate } \\
\text { the closely interlinked site elements. } \\
\text { Stonework } \\
\text { There is extensive deterioration of both cut bedrock } \\
\text { and laid stone elements, however most of the } \\
\text { deterioration is difficult to rectify as it relates to } \\
\text { water and wind action, both of which in most } \\
\text { situations cannot be rectified. More isolated } \\
\text { deterioration due to steel rusting etc. can, if critical } \\
\text { be repaired. The major issue is removing water from } \\
\text { the site to slow deterioration. Monitoring is } \\
\text { essential. } \\
\text { Concrete - There is considerable deterioration of } \\
\text { concrete work around the site through spalling with } \\
\text { rusted steel elements, cracking of poured concrete } \\
\text { elements, delaminating of concrete pours. The more } \\
\text { obvious examples are ceilings where rusted steel } \\
\text { beams have resulted in a loss of bottom cover and the } \\
\text { plastered finish, this will be ongoing. } \\
\text { The second world war concrete elements feature } \\
\text { rusting reinforcing (not found in earlier concrete) } \\
\text { that will either require extensive repair or some loss. } \\
\text { Cracking in structures requires concrete grouting to } \\
\text { prevent water entry and increasing deterioration. } \\
\text { Steelwork - The steelwork is largely the roof support } \\
\text { structures with mass concrete poured over them, } \\
\text { long-term water ingress has resulted in rust. While } \\
\text { in most cases deterioration is slow it will inevitably } \\
\text { result in structural failure of some areas. Support } \\
\text { structures may be required over time to prevent } \\
\text { failure; this has already been installed in some } \\
\text { locations. }\end{array}$ & $\begin{array}{l}2 \text { Undertake conservation works } \\
\text { to drainage systems to remove } \\
\text { water from the structures. HIGH } \\
3 \text { Replace severely damaged } \\
\text { stones if failure is imminent. } \\
\text { LOW } \\
4 \text { Remove deteriorated stone } \\
\text { debris from floors to prevent } \\
\text { blockages to drains. HIGH } \\
5 \text { Repoint joints as they fail. } \\
\text { MEDIUM } \\
6 \text { Investigate steel treatments to } \\
\text { deteriorated steel elements to } \\
\text { reduce the rate of deterioration of } \\
\text { exposed elements particularly in } \\
\text { roof support beams. HIGH } \\
7 \text { Monitor concrete deterioration. } \\
\text { MEDIUM } \\
8 \text { Undertake a grouting program } \\
\text { to fill minor cracks and stabilise } \\
\text { at risk concrete work. HIGH } \\
9 \text { Prepare a program of repair and } \\
\text { reinstatement of damaged } \\
\text { concrete elements seen in } \\
\text { cracking of concrete around } \\
\text { rusted steel, structural cracking } \\
\text { of concrete, surface cracking of } \\
\text { finishes. HIGH } \\
10 \text { Investigate steel treatments for } \\
\text { exposed at risk steelwork to } \\
\text { reduce the rate of deterioration. } \\
\text { HIGH }\end{array}$ \\
\hline
\end{tabular}




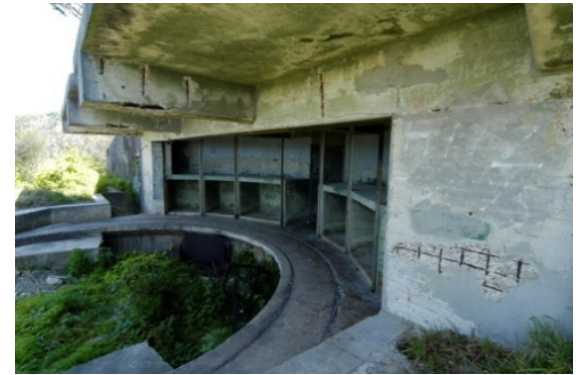

Figure 2: A WWII gun position with advanced deterioration of concrete and steelwork.

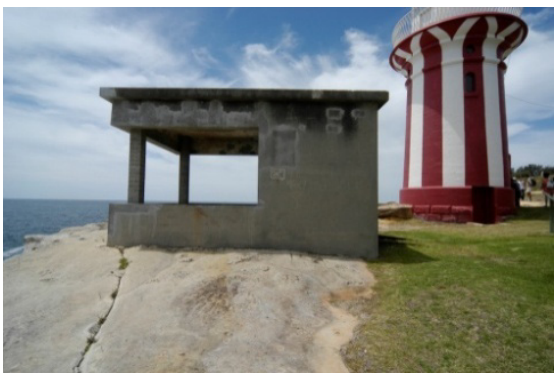

Figure 3: A conserved WWII observation post with steel posts replaced with concrete block and concrete and steel repairs.

\subsection{Using existing information and researched techniques}

A key strategy is using the information already obtained for specific sites for use across all the sites with similar issues. This had not been done before this. Detailed analysis of deterioration of stone, concrete, brick and steel elements in below ground, marine environments with conservation methods (and how the methods have been undertaken both with and without success) is key information to apply across the broad range of sites and places.

It became clear that a lot of research had been undertaken on 'unique' conservation problems but not as much work on broader more common issues. Developing good standard approaches to conservation, such as steel deterioration and treatment, is essential to conserve the large number of fragile structures.

There is also a tendency to ignore conservation works once they have taken place on the basis that once conserved the place is fine. Detailed inspection of earlier works indicated that most conservation work required monitoring and follow-up work to maintain the works in good condition and to prevent the loss of benefit from often-expensive works. An example is the application some 15 years ago of a waterproof membrane to the roof a large underground casemate installation. Extensive research to select a membrane system was undertaken and the work was carried out carefully and well, however there is now a breakdown of sections of membrane taking place that requires quick repair to prevent a largescale loss and the need to reapply the whole membrane. As the sites were not regularly monitored and inspected this was not observed and there was a high risk of a membrane failure that could have been avoided. Also arising from this is the ability to review the membrane selection to see how it performed over the time of its application. This can inform future similar decisions.

\subsection{Managing public access and risk}

One of the most difficult compliance issues is public risk in accessing remote, unmanned and often dangerous sites. It is not possible to make abandoned 


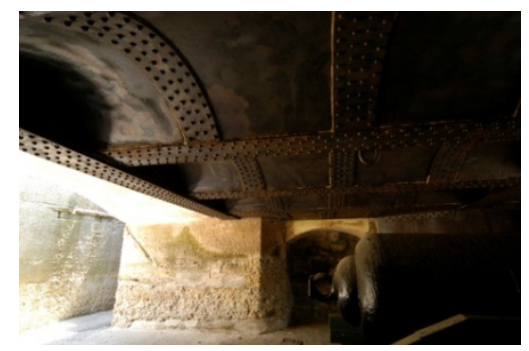

Figure 4: The interior of a conserved casemate at Bare Island. This is one of the few sites retaining ordinance that related to the use of the site. The ordinances are generally well conserved with great interest in their retention.

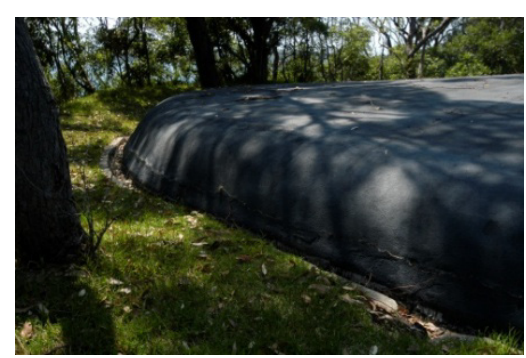

Figure 5: The membrane over a Georges Head casemate showing signs of deterioration around its edges. This area has open public access.

defence sites comply with current access and building codes, nor is it acceptable to close the sites to future access. The strategy proposed was to provide safe and as complying access as possible to key locations with defined paths, stairs and ramps and to protect any non-complying changes of level (such as lookouts) where defined public access was provided. Other areas would have lesser levels of intervention and protection aimed to identify where risks may be present. For example at Middle Head there is an extensive grassed area around a series of gun emplacements where there are pits of 3-4 metres depth, the area is used for picnics with children and the changes of level are hard to see, here a simple railing was provided several metres away from the change of level to indicate that the area was separate and should not be accessed. The railing is visually minimal but a clear indicator of risk.

An approach to providing signs at entry points advising that the area contains fortifications that are not protected and that the public should use established paths and routes for access.

A further aspect of this was to secure underground areas from general access except for ones that were established with safe and managed access. Specific tours were also established to allow the public to visit some of the more remote and fragile interiors and below ground areas.

Another strategy has been to selectively remove dangerous elements such as rusted steel projections to reduce the risk of injury when these sites are accessed. Again the spread of sites and the remoteness of some in heavy bushland make even monthly inspection difficult. For some WWII above ground structures that have deteriorated to the point of imminent collapse, the strategy has been to remove those parts of the structures that are dangerous and to stabilise the sites in that condition. 

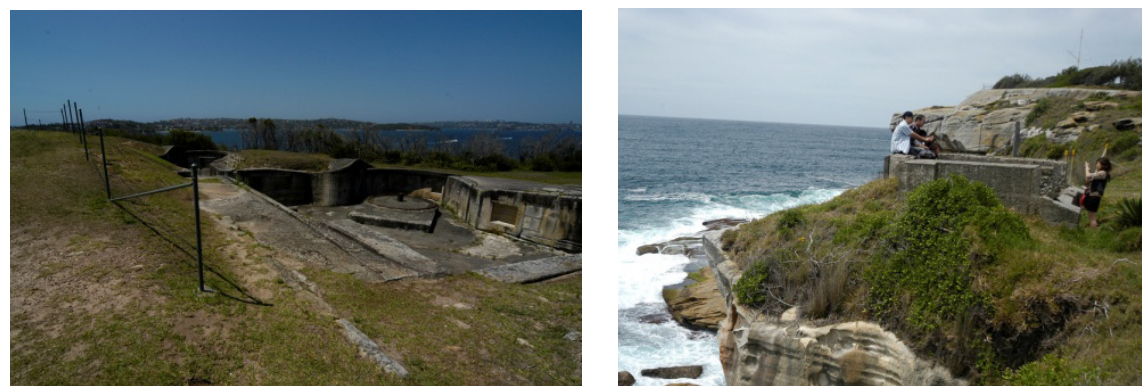

Figure 6: Outer Middle Head showing more recent fencing that is properly placed at the top of the rise to prevent casual access to steep slopes. It does not prevent access but provides a suitable indicator to prevent a visitor from accidentally accessing a difficult area. While the form of fencing is not sophisticated, it is low key and works well.

Figure 7: South Head adjacent to Hornby Light showing the difficulties of unprotected access to cliff top features. This is a highly visited location that is used for many photographs and has high risk due to the dangerous behaviour of visitors. Here a barrier, possibly low and behind this popular photo location would reduce risk.

\subsection{Vandalism}

Vandalism has been an ongoing problem on fortification sites due to their remoteness and lack of other activity. There are two types of vandalism: painting and general defacing which is annoying but not dangerous and removing and breaking into underground areas leaving them accessible and dangerous. As elsewhere in the world there is considerable interest in breaking into abandoned sites and despite very secure gates and doors, they are accessed. Many of the underground facilities are not safe, are at risk of collapse and contain asbestos and other dangerous products. One management strategy for remote and very dangerous sites has been to backfill entry passages and shafts with sand to make access impossible.

\subsection{Managing landscape and setting}

All of the former fortifications are now located within a National Park that is principally established for its natural values. While there is a clear direction to conserve cultural heritage, there is often conflict between natural and built 


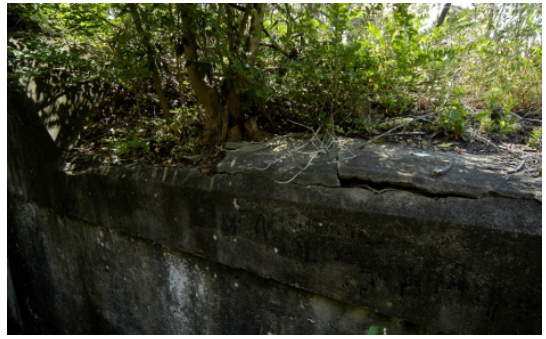

Figure 8: An example of encroaching vegetation and the damage that takes place through poor site management. This has general public access.

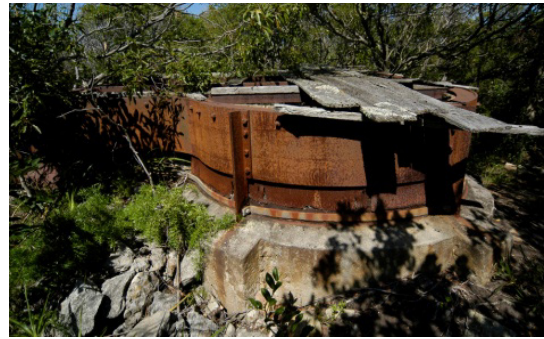

Figure 9: $\begin{array}{lrr}\text { A surviving } & \text { gun } \\ \text { emplacement at } & \text { Middle }\end{array}$ Head. While accessible it is almost impossible to access, regrowth has removed its setting and context.

heritage and how they are managed. It is important to retain the natural vegetation as it has regrown on all of the sites, but it also imperative to provide a suitable setting around the various fortifications and to remove invasive and damaging growth. For the most accessed and well-managed sites this is achieved, but on most of the sites vegetation has overtaken the structures often with very damaging results. The strategy has been to identify where actual damage is taking place or likely to take place and as a first stage to remove those natural elements to save the built fabric. However this is a labour intensive and costly exercise that is usually overlooked unless there is an imminent danger.

Establishing clear principles on how to maintain edges between natural and managed landscapes and how to limit regrowth on and adjacent to built heritage is essential. On some remote and overgrown sites the policy is to allow regrowth to envelop and take over the structures as other management options are not realistic and the ongoing management of the sites is unlikely to take place.

\section{Conclusion}

The outcome of the strategic plan for this complex set of sites and structures was in some aspects depressing as it was clear that there was no way to conserve and properly present most of the sites. The extent of basic conservation work was beyond any potential funding, staffing the sites was not affordable, safety issues were wide spread and required decisive and dramatic solutions, accessing underground and fragile sites was largely unmanageable, the natural settings and landscape were largely out of control in relation to the built heritage fabric and the sites could not be effectively monitored. The core recommendation, to focus on the two most publicly accessible, visitable and interesting sites and to effectively mothball, with minimal works, the other sites, was a radical solution that has not really been adopted, even though parts of the strategy are being 
implemented. This highlights the difficulty of working with government agencies who have excellent personnel but fast changing political situations that affect long-term planning.

The only way to make an impact on the many needs of these core sites is to establish sound and clear management practices (as indicated above) and to put forward a convincing business case linked to tourism, potential leasing of parts of sites, good public access and a range of value-added activities that could link to the sites. These sites will never pay their way, are almost impossible to adaptively re-use but, with innovative thinking, they can go some way towards viability and create extraordinary public places and experiences.

\section{References}

[1] NPWS Archives and Records.

[2] Oppenheim, P. The Fragile Forts, The Fixed Defences of Sydney Harbour 1788-1963, Australian Military History Publications, Canberra, 2005.

[3] Davies, P.R. NPWS Fortifications Strategic Plan, 2007. 